\title{
The Reflective Learner: Perspectives of Engineering Faculty Engaged In Learning through Service
}

\author{
Bowa George Tucker* \\ James B. Francis College of Engineering \\ University of Massachusetts \\ Lowell Lowell, Massachusetts 01854 \\ Bowa Tucker@uml.edu \\ * Corresponding author \\ Angela R Bielefeldt \\ Department of Civil, Environmental, and \\ Architectural Engineering \\ University of Colorado Boulder \\ Boulder, Colorado 80309 \\ Angela.Bielefeldt@colorado.edu \\ Olga Pierrakos \\ Department of Engineering \\ James Madison University \\ Harrisonburg, VA 22807 \\ pierraox@jmu.edu
}

\author{
David O Kazmer \\ Department of Plastics Engineering \\ University of Massachusetts Lowell \\ Lowell, Massachusetts 01854 \\ David_Kazmer@uml.edu \\ ring

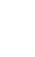

Kurt Paterson

Department of Engineering

James Madison University

Harrisonburg, VA 22807

paterskg@jmu.edu

\author{
Annie Soisson \\ Center for the Enhancement of Learning \\ and Teaching \\ Tufts University \\ Medford, Massachusetts 02155 \\ Annie.Soisson@tufts.edu
}

\author{
Chris Swan \\ Department of Civil and Environmental Engineering \\ Tufts University \\ Medford, Massachusetts 02155 \\ Chris.Swan@tufts.edu
}

\begin{abstract}
Over the past decade, Learning through Service (LTS) has proliferated in higher education as an effective teaching and learning method. LTS is an umbrella term that includes both curricular and extracurricular activities, recognizing that there are many models that exist currently for how faculty members use opportunities for students to learn while providing service to a community. Reflection by the students on their service activity provides rich opportunities for students to add meaning to their learning through engagement with community. While, many colleges and universities in the United States have increased the use of LTS in engineering programs, there has been limited study to evaluate engineering faculty perception of the purpose of reflection in support of facilitating and assessing the expected learning outcomes. In this research, twenty-six interviews were conducted with engineering LTS practitioners to explore how and why
\end{abstract}


International Journal for Service Learning in Engineering

Vol. 9, No. 2, pp. 29-46, Fall 2014

ISSN 1555-9033

\begin{abstract}
engineering faculty incorporate reflection in LTS efforts. The findings reveal that majority of engineering LTS faculty practitioners engage students in reflection to enhance the professional development skills of their students, with fewer of the faculty using reflection to develop students' personal skills.
\end{abstract}

Index - Learning Through Service, service learning, reflection

\title{
INTRODUCTION
}

Constructivist theories of learning suggest that students generate understanding and meaning through the synthesis of their experiences. ${ }^{1}$ Dewey posits that "real knowing" is a rigorous process of reflective thinking. He asserts that real knowing occurs only through a reflective or inquiry process to solve a problem which has created disequilibrium within the learner. Hence, reflection is the meaning-making process that moves a learner from one experience to another. ${ }^{2}$ Vygotsky surmised that each student has a unique and transient zone of proximal development. ${ }^{3}$ If scaffolding is appropriately provided, the student's range of expertise can be broadened with knowledgeable support of a peer or instructor beyond what the learner could do alone. ${ }^{4}$ This literature consistently suggests that mastery of complex skills depends on an interlocking set of experiences and instruction whose efficacy, in turn, depends on the learner and the community of practitioners with whom the learner interacts. ${ }^{5}$

Learning through Service (LTS) is an umbrella term that includes both curricular and extracurricular activities, reflecting that there are many models that exist currently for how faculty use opportunities for students to learn while providing service to a community (locally and globally). These pedagogies of engagement include experiential education, collaborative learning, problem-based learning, and service-learning. ${ }^{6}$ For instance, service-learning is a curricular teaching method in which students participate in an organized service activity for academic credit that meets identified community issues, and the reflection done by the students on their service experience furthers their understanding of course content. ${ }^{7,8,9,10,11,12}$

In addition to curricular approaches there are many extracurricular activities, including global learning opportunities such as the activities of Engineers without Borders, that are not formally part of the curriculum but still provide opportunities for students to learn through service with reflection. Both curricular activities including service-learning and extracurricular activities including Engineers without Borders can, in fact, be considered a form of community service. The community service activity must be a worthwhile one that the community wishes to have done. It also must be one in which the students and the community must find relevant and meaningful. ${ }^{13}$

The purpose of this study is to understand why engineering faculty incorporate reflection in their LTS efforts. The following research questions guided this study:

1). Why do engineering faculty integrate reflection in their LTS efforts?

2). What are the expected learning outcomes? 
This inquiry examines faculty intentions and methods regarding reflection in their LTS programs with the intent to provide insight on the meaning faculty attach to understanding the role of reflection. Since the development of LTS falls under the purview of the faculty, and its purposeful implementation requires revision of courses in both curricular and in extra- curricular activities, the focus of this study is faculty who implement LTS.

Some scholars have written about the struggles engineering faculty face in integrating effective reflection in learning through service. For instance, Tsang posits the words "reflect" and "reflection" have negative connotations among engineering and technology faculty. ${ }^{14}$ In his view, this is attributed to a focus on technical training with a lack of reflection, as well as a lack of reflective course materials available to engineering and technology faculty. As such, Tsang proposes the use of a Reflective Rubric to assess the performance of students in understanding the impact of engineering and technology on society.

Similarly, Slivovsky et al. posits "one of the traditional barriers to integrating reflection into engineering courses has been the perception or stereotype that reflection is an activity that would fit into a humanities course but not an engineering course." 15

They advance a model beyond the traditional service-learning reflection (ethics and social context) where the focus is on the social, political and cultural impacts of engineering technology on society to include reflection on the community partner. Although they point out the assessment of their EPICS program revealed that $10 \%$ of students self-reported an increase in community awareness, very limited empirical studies in engineering have been conducted to discern not only why faculty integrate reflection in their LTS content, but also what is the expected learning outcome for students.

The issue of adequately preparing engineering students with technical knowledge and the professional skills needed to solve global problems in the $21^{\text {st }}$ century has become prominent in the academic literature in the past decade. ${ }^{16,17}$ As the demand for preparing engineering students with professional skills continue to increase, the ability to educate students to play an active role in a globalized world is becoming more important. This study determines how faculty view "reflection" and what are the expected learning outcomes. These findings can assist engineering faculty and administrators in creating the opportunity to better align LTS course content with the skills required of engineers in the $21^{\text {st }}$ century.

\section{LITERATURE REVIEW ON LTS TEACHING AND LEARNING}

Researchers have called attention to models of teaching based on students as active learners and collaborators in the teaching and learning process. ${ }^{18,19,20}$ Table 1 delineates the differences between lecture ("old" paradigm) and a "new" paradigm of teaching. Reflecting on this "new" paradigm, there seems to be another shift in student centered learning. Thus, rather than view learning outcomes from a teacher-driven lecture approach, or what Friere considers the "banking model of education" which emphasizes depositing information into the minds of passive students, ${ }^{21}$ learning should be viewed through a more holistic and complex lens. ${ }^{22}$ 
TABLE 1

Old ANd New Paradigms of Teaching

\begin{tabular}{|l|l|l|l|}
\hline & "Old" Paradigm & "New" Paradigm \\
Paradigm \& \\
Illustration
\end{tabular}

Johnson's "new" approach to learning focuses on a learner-centered environment in which students work in collaboration with the teacher to solve problems rather than submit passively to the teacher. The learner-centered approach, therefore, enables students to participate in decisions that affect them. In addition, teachers provide students with opportunities to contribute to the learning process. It provides situations for students to develop habits of reflective thinking that enable them to make informed decisions about social actions. ${ }^{23}$ Thus, when social problems are studied, students do not simply memorize information, they also learn how to use subject matter to understand societal problems and issues.

We propose that Johnson's "new" approach has itself become outdated with the advent and broad adoption of social networks and web-based content. Specifically, the web-based content allows for information and knowledge to be globally shared (e.g. Wikipedia) through numerous peer to peer forums. In this context, students become problem solvers and the role of faculty is to act as a coach or facilitator, encouraging and guiding students to access resources to solve problems. Learning in this context is highly social with relationships occurring on an ad hoc basis with peer to peer interaction as warranted. The assumption in this model is that students are self-actualizing. 
We hypothesize that students that are not self-actualizing are more likely to fail in their academics as well as the globally competitive workplace. Thus, the role of the faculty as a coach and facilitator is increasingly important. How do students find relevance and meaning in understanding societal problems and issues? Scholars found that reflection on experience is the basis of knowledge construction and that social context shapes our conceptions of knowledge. $^{24,25,26,27}$ Students gain a deeper understanding of their relationships and connections to their experiences and ideas as well as the experiences of others. Learning through service helps to foster connections between the complex concepts of community action and service, including the complex political, economic and social issues that surround them. ${ }^{28}$

Hence, reflection is the meaning-making process that moves a learner from one experience to another. As a consequence, reflection is an indispensable pedagogical component of learning through service that "helps students contemplate their service activities" [to] "reformulate assumptions, create new frameworks, and build perceptions that influence future action." 29

Additionally, Eyler posits that reflection is the hyphen between service and learning in service-learning, and reflection is the process that enables students to link course content with what they observe and experience in the community. ${ }^{30}$ Springer \& McKnight Casey suggest students should be required to reflect not only on their project, but also on their own learning, the issues leading to the community need for service, and what it means to the community partner/clientele. ${ }^{31}$ As such, reflection provides the means for the students' self-assessment of their disciplinary knowledge, and learning about their community partner/client from their community service experience. Therefore, reflection is a process of thinking that allows students to critically examine their own learning and the learning about their service experiences with the community partner. The process is manifested through various medium including blogs, journal writing, oral presentation, and group discussions which enables faculty to assess student learning. Depending on how faculty integrate reflection, students can either reflect alone by writing about their learning experiences in a journal, online discussion with classmates, or by doing an oral presentation for their classmates and/or the community partner. Each option brings a different layer to the reflective process and the more time students have to reflect on their experiences the greater connection between their experiences and the learning objectives of the class.

Therefore, in the case of engineering, Tsang advances "the purpose of reflection materials is for students to examine the societal aspects of engineering and technology by examining the larger issues behind the needs to which the service-learning projects are responding and to explore the professional and ethical responsibilities of an engineer by focusing on doing the work of an engineer responsibly and well, whether in the workplace or in the community service."32 Through the process of reflection, LTS can assist students in constructing meaning from their community experience and can be a powerful tool for enhancing the technical and professional skills of engineering students.

However, although LTS can be an effective tool for enhancing the technical skills of engineering students, it is not enough to simply implement LTS without taking into consideration 
the desired learning outcomes. In order to effectively measure the desired learning outcomes, it is necessary to purposefully incorporate reflection in the design of LTS efforts. It is hypothesized that engineering faculty, not formally trained or necessarily aware of the standard use of reflection in the social sciences, may not be providing LTS students with rigorous reflection as part of the learning and assessment process.

\section{THEORETICAL FRAMEWORK}

In terms of the theoretical underpinnings in the literature, researchers have employed a number of theoretical perspectives to better understand and guide research on community oriented learning outcomes. These frameworks are often drawn from a variety of disciplines. A brief overview of some of these frameworks are presented before discussing the approach taken for this study. For example, in terms of the outcomes of skills and knowledge needed for effective citizenship, Battistoni posits that "there are multiple pathways for civic engagement and if we want to encourage citizenship throughout the university and across the curriculum, we need to leave room for multiple perspectives, even as we attempt to be deliberate in our effort" (p.11). ${ }^{33}$

Battistoni developed a framework from the social sciences and argued that "if we want to engage all across campus in education for civic engagement, we need to go beyond the social sciences for conceptual frameworks that will inform the theory and practice." Hence, his framework distinguished between twelve conceptual models of citizenship and identified the following eight skills as critical for engaged citizenship: (1) political knowledge and critical thinking, (2) communications skills, (3) public problem solving, (4) civic judgment, (5) civic imagination and creativity, (6) collective action, (7) community coalition building, (8) organizational analysis.

To some engineering faculty, Battistoni's framework based on social science may seem remote. However, the concept of civic engagement in the engineering profession is not new, as Newell stated: "in its ideals the engineering profession is not surpassed by those of any other group of public servants." ${ }^{34}$ Still, the scope of service varies broadly with the application of the engineering discipline as well as the values of the individual practitioner. The importance of civic engagement is increasingly incorporated in engineering disciplinary and professional standards by ABET (Lang, Cruse et al. 1999). ${ }^{35}$

There are also other relevant frameworks. For example, drawing from the work on cognitive psychology, Eyler et al. have found the expert-novice conceptual lens to be a useful framework for understanding the acquisition, storing and recall of information by students during community service learning. ${ }^{36}$ A key element of the expert-novice literature suggests that there are real differences in the structure of knowledge between experts and novices and how they reason about a problem. Thus, like experts, students with long-term involvement in community service have a different way of reasoning about the nature of social problems and how they structure their knowledge from those who are newly involved with community service or those whose understanding is limited by what they learn only in the classroom. 
Eyler et al. posit that students with prolonged involvement in community service are able to define community problems and potential solutions within specific community contexts, and hence, community service learning can help students develop complex and constructive understanding of the issues they will face. From this expert-novice perspective, community service experiences may be structured to boost students' civic development. ${ }^{37}$

While the above frameworks are important foundations from which to view students learning outcomes, the framework adopted for this study is from "Motivational Perspective on Self-Regulated Learning." "38 It provides a lens through which to view faculty-intended outcomes of reflection in LTS. According to Valle, Cabanach, Rodriguez et al. the approach is initially drawn from social psychology and derives from Bandura's socio-cognitive perspective. They define Self-Regulated Learning as "an active process in which students establish the goals that direct their learning, attempting to monitor, regulate, and control their cognitions, motivation, and behaviors in order to achieve these goals" (p. 310). They argue that self-regulated learning unlocks new ways of reflection that offers an in-depth and more self-motivated approach to the understanding of the learning process.

This conceptual model relies on students playing an active part in the course of knowledge construction. While faculty might have intentional learning outcomes from engaging students in reflection, the basic principle of self-regulated learning assumes the learners are the agents who choose and make decisions about their behavior. However, intervention is suggested in terms of the contextual and instructional factors affecting self-regulation and how students become self-regulators of their own learning. ${ }^{39}$

This framework is useful for this research project because of its emphasis on reflection and how students learn. Since reflection plays a critical role in adding meaning to student learning in addressing issues of public concerns, self-regulated learning is a useful analytical framework to examine faculty intentions and actions that guide self-regulated learning. It is also useful because understanding the professional learning outcomes is related to the design of LTS and the projects that seek to produce certain professional skills.

The framework has important implications for LTS research in that it reaffirms the importance of linking reflection to professional learning outcomes and what LTS faculty practitioners do to help students acquire these skills. In particular, it points to the centrality of faculty intentions in incorporating reflection and how reflection promotes self-regulated learning to guide the associated professional skills the faculty members intend to teach.

\section{DATA COLLECTION METHOD}

A qualitative multi case-study approached was used to examine context of faculty use of reflection in LTS. Twenty-six faculty members were interviewed. The first round of interviews consisted of 11 interviews and was conducted face-to-face for approximately forty-five minutes at an LTS workshop. The remaining interviews were conducted over the phone with LTS workshop participants. The research questions guided by this study linked the data by utilizing semi-structured interview techniques to generate data from the twenty-six cases. 
Stake maintains that interviewing case study participants provides the researcher with a primary source of data which reflects the multiple realities of the phenomenon being studied. ${ }^{40}$ Interviewing is the process of gaining participants' perspectives through the art of questioning on the problem or issues under investigation. ${ }^{41}$ This process provided an opportunity, as noted by Glesne, "to capture the unseen that was, is, will be or should be; how respondents think or feel about something; and how they explain or account for something" (p.3). ${ }^{42}$

Interviewing as a data gathering technique offered several advantages: (1) useful when participants cannot be observed directly; (2) participants can provide historical information; and (3) allows researcher "control" over the line of questioning in the interview process. However, there are several limitations to this approach, which include: (1) indirectly filtering information through the views of the interviewees; (2) information is being provided in a designated place instead of the natural setting; (3) the researcher's presence may bias the interviewees' responses; and (4) interviewees may not be articulate or perceptive. ${ }^{43}$ The interviews were audio taped for purposes of transcription. Upon completing transcription of the interviews, the data was coded and analyzed.

\section{FINDINGS}

Analysis revealed several key themes from the interview data. The themes are presented below in two major categories. The first category focuses on promoting "professional development" as the primary reason for faculty use of reflection and the second category focuses on promoting "personal development." We begin by illustrating the themes that emerged from faculty reasons for engaging students in reflections for "professional development."

\section{Learning about the community and its needs}

The data indicate that a key reason for faculty integration of reflection in LTS is to help students learn about the community. Accordingly, for majority of the faculty, reflection is intended to give students the opportunity to learn about the community through first-hand experiences. The first-hand knowledge of the community is therefore the first step for student engagement in the community. This is true for both curricular and extra-curricular activities. As noted below by one faculty with many years of experience with an extracurricular program:

"I'd say that the way that we run our EWB [Engineer without Border] program here places quite a strong emphasis on understanding the community before trying to come up with a solution. And we've had that very powerfully reinforced in the recent past, and we've talked with community, and their priorities... I tell students something that they've experienced, they're well aware that we need to be addressing the community's needs." 
International Journal for Service Learning in Engineering Vol. 9, No. 2, pp. 29-46, Fall 2014

ISSN 1555-9033

Another faculty involved in a curricular LTS states:

"I try to help students understand that for example if they go do a project in Mexico, the historical and political context of Mexico is very different than Guatemala or Panama or Colombia or Peru even though all these countries are in Latin America. So I help them appreciate that each country has a very distinct historical, political, cultural context that they need to understand before they attempt to implement a project there."

Reflection, according to faculty, was intended not only to identify the needs of the community but to also better understand the particular community in which students were learning. The faculty provided students with the opportunity to know the community to address a given problem in that community. For example, one faculty states:

"They [students] spend two months at least trying to understand the problem, understand the communities. So they immerse themselves in the community, they take videos, they take pictures, they look at people using some technologies, they look at people, community, their lifestyle, their culture and in terms of [program deleted] they do it in Ghana, basically Ghana and Mexico right now. So we look at people there."

Reflection is used to provide answers to questions. One faculty is noted to state:

"How can we do this well, and how can we assure that we are meeting these local needs? We really encourage the students and the faculty members to engage in the communities where they're working. So usually those interactions are what helps sensitize students to the particular, you know, social or community needs or problems that those communities are having."

From a professional standpoint, students learn about the community by interacting with community members through analysis, through critical thinking, and synthesis of what they learn. They use this knowledge to indicate the need for gathering more information, presenting information, or advocating for a particular point of view or action with regard to the pressing community issue.

\section{Providing better solutions to the community}

In addition to learning about the community to identify its needs, another important finding for involving students in reflection is to help students think about effective design solutions. One faculty states:

“it's [reflection] a critical part of the reflective learning process whereby asking students to reflect on their successes or failures, it can enable really development of their abilities as professionals who are engaged in solving problems for real world clients so I think it's an essential part of practice, and I think it scaffolds the learning process for the students, and I think one additional important outcome is that it helps lead to better solutions for our communities and clients that we're serving." 
Another faculty states:

"I think what this experience helps with is having them [students] realize the need to integrate these, you know, small design tasks into a much bigger process, into a much larger process as a project or - I mean I guess you could almost call it project management, but to recognize that, you know, making sure that you're designing the right thing for the right situation is as important as, you know, doing a proper design or understanding the equation that might be driving the design."

Through community interaction, students are ably guided to better solutions for the community. They develop the technical competencies necessary to be an effective professional engineer to solve real-world problems. From the perspective of the faculty, community experience deepens students' knowledge of the problem and it enhances the practical understanding of engineering solutions. Hence, faculty practitioners were interested in making sure that students reflect on how their involvement in the community, and how their proposed solutions to community problems, contribute to improving the lives of community members within the context of engineering.

\section{Reinforcing lessons learned}

Another key finding was to ensure that students reflect on their learning. Most of the faculty cited the need for students to think about the lessons they learnt from the course content and the relevance of their community experience. As stated by one faculty:

"I think it's to see what the lessons learned experiences are. Because if you just go down there and then come home, and that's it, I think you're missing a real part of comparing what your original goals were to how it actually turned out and the other things that you learned."

Another faculty states:

"Primarily to help them realize what they have learnt and also to help them understand what they have done the previous week and then look forward to the next week and be a little more strategic rather than making decisions more spontaneously and how they are going to move forward on the project."

This view is further supported by another faculty:

"I think for me the purpose of that [reflection] is to really try to get students thinking a little bit - maybe a little bit more broader, maybe little bit more big picture than just focusing on the engineering project itself... anybody's who is a professional engineer who's a successful engineer is going to say, does my answer make sense, is it off an order of magnitude?" 
The faculty perception of the use of reflection is to stimulate students' thinking about their learning. The lessons learnt is basically how to connect disciplinary-based knowledge in socially responsible ways. Specifically, it is about their mistakes and how to make corrections.

\section{Summary of Themes Related to Professional Development}

The majority of the faculty viewed the importance of reflection is to shed light on students' professional responsibility from an engineering context when addressing community problems. In the view of the faculty members, preparing students to acquire knowledge of an engineer to address challenging issues in the community enhances the professional skills of the students. Therefore, the self-reflective process enables students to achieve a better grasp of underlying social problems. Hence, knowledge of the community to identify problems in the community in order to produce effective solutions, and thinking about the lessons learnt in the process, clearly emerged as a themes for enhancing professional development for students.

While the majority of the faculty did not explicitly state communication skills as an outcome of reflection, the process of engaging in discussions with faculty, interacting with the community by asking questions of the community partners, and then coming back and giving community the results involves the development of communications skills. Through the skills acquired from the community learning experience, students developed the ability to listen, the ability to negotiate, the ability to ask the right questions to acquire information, the ability to problem-solve, and the ability to analyze and synthesize information through critical thinking with regards to social issues to attempt to solve. These are skills which are necessary to function as a professional engineer.

\section{Personal Development and Self-Awareness}

Now the discussion turns to the theme that emerged from personal development. While a majority of the faculty referred to themes related to 'developing the professional engineer', some of the faculty viewed reflection as a way to help students examine their personal skills and objectives. One faculty states:

"The reason I integrate it [reflection] in my teaching is because I want my students to be able to be introspective and you know, the unexamined life isn't worth living and to be intentional about the things that they are considering and the way in which they are moving through the process, how this process is impacting them and how their impact in this process is critically important to the process itself."

Another faculty states:

"I primarily use it [reflection] to help students see their own identity beyond what the social norms of an engineering college would suggest that they should be. It helps them to see beyond that view. In other words if you are an undergrad and you are in an engineering curriculum, your life will not simply be doing calculations and solving 
problems, your life will not be hanging out with other engineers, there's more to you than just that. It's remarkable to see students how refreshed they feel suddenly realizing it's okay to talk about another about part of themselves and have that valued.

Furthermore, another faculty states:

"I think reflection is one way to assist students with some of the cognitive, affective, paradigm shift, emotional difficulties, challenging issues and experiences that they have."

In terms of personal development, the faculty perception of the use of reflection is to help students think about who they are as individuals and the role that they can play in the larger process of community transformation.

In most LTS situations (local and especially international) students are often in situations where they are interacting with people who are often different from themselves. For example, when students provide service in a different culture from the one they grew up in, their own culture becomes more obvious to them in the encounter with others. As such, some faculty viewed reflection as providing the opportunity for students to become self-aware.

\section{DISCUSSION}

One of the research questions for this study was to assess how engineering faculty members who engage in LTS efforts conceptualize the purpose of reflection. The findings revealed three essential themes for developing professional skills and one overarching theme for developing personal skills. The professional development skills themes consisted of the following: 1) learning about the community to identify its needs, 2) providing better solutions to the community, and 3) reinforcing lessons learned.

In terms of personal development skills, the focus was on self-knowledge or awareness of the self. These are all essential skills for preparing the professional engineer.

One key understanding from the analysis is that the majority of faculty in this study viewed reflection as a way to help acquire the professional skills needed for the professional engineer. In their view, a common strategy to developing students' professional skills was for students to reflect on problems in a specific social setting. This is an approach that enables students to work with the community to solve problems and understand complex technical concepts.

Through interaction with the community, students are expected to be able to identify community problems and develop solutions within specific community context. Hence, the faculty involved students in reflection to ensure that students feel empowered to respond to intricate community issues by highlighting a need, and by providing useful information to address a community issue. Therefore reflection enabled students to better understand complicated community problems. The faculty widely believed that the students' ability to grasp course concepts increased significantly when students connect course materials to their 
engineering activities in the community. Therefore, it was not surprising to note the development of professional skills from the point of view of the faculty were associated to students' reflection of their learning in the community.

It appears the central goal of reflection for these faculty members is influenced by ensuring students meet all of the ABET a-k outcomes. ${ }^{44}$ The situation in which students were placed in the community to reflect on their learning of relevant subject areas was critical in defining how students respond to addressing problems in the community from an engineering perspective. Reflection provided an opportunity for students to realize first-hand the knowledge they will need as professional engineers along with the technical skills for solving problems in the community. Although communications skills was not stated as an explicit outcome of professional development skills, communication skills are essential to student success in interacting with the community to identify the needs and to provide better solutions, as well as, to identify the lessons learnt.

Interestingly, a minority of the faculty members explicitly emphasized the use of reflection as a way for students to develop self-knowledge. Self-knowledge is consistent with personal development skills. ${ }^{45}$ What this suggests is that when students become self-aware, they are put in a much better position to learn about their strengths and weaknesses in the way they learn. It enables students to question their assumptions about themselves and their role in the larger process of solving complex engineering problems in the local and global community.

The result from this research indicates that context plays a big role in identifying the meaning instructors attach to student learning. As such, self-regulated learning is critical for students to learn how to learn because reflection is about the construction of the meaning students attach to their learning. Reflection is a learner-centered approach that enables students to participate in decisions that affect their learning, and serves as a tool in assessing the learning that is taking place. While the process is learner-centered, Valle, Cabanach, Rodriguez et al. posit intervention is suggested in terms of the contextual and instructional factors affecting selfregulation, and how students become self-regulators of their own learning. ${ }^{46}$ In other words, the learning situation and the instructors influence what students need to know and regulate in their learning.

\section{CONCLUSION}

The results from the research indicate that engineering LTS practice does not vary significantly from common practice in the social sciences. In both the social sciences and in engineering, communication is critical to creating educative experiences. Hatcher \& Bringle, states "communication with others leads not only to educational growth but also to social and moral development." 47 While some engineering practitioners use reflection to enhance the personal skill of self-awareness for their students, the majority of the engineering faculty practitioners are driven to develop the students' professional and technical skills. Hence, the ability to communicate effectively with the community is necessary in order to learn about the community to identify and provide better solutions. An irony perhaps is that self-awareness is the basis for 
International Journal for Service Learning in Engineering

Vol. 9, No. 2, pp. 29-46, Fall 2014

ISSN 1555-9033

personal growth which leads to developing the motivation and self-actualization that is critical for professional development. The overarching question emanating from this research that may inform future pedagogy is: which should come first, social or technical development? Should reflection be driven by the need to first and foremost enhance professional skills and technical development or personal communication skills and social development? We as faculty need to further consider and better implement reflection in our roles as coaches and facilitators in the increasingly global network of learners and practitioners.

\section{REFERENCES}

${ }^{1}$ Dewey, J. (1916). Democracy and education, MacMillan.

${ }^{2}$ Mills, J. E. and D. F. Treagust (2003). "Engineering education-Is problem-based or projectbased learning the answer?" Australasian Journal of Engineering Education 3: 2-16.

${ }^{3}$ Vygotsky, L. (1978). "Interaction between learning and development." Readings on the development of children: $34-41$.

${ }^{4}$ Applebee, A. N. and J. A. Langer (1983). "Instructional Scaffolding: Reading and Writing as Natural Language Activities." Language arts 60(2): 168-175.

${ }^{5}$ Brown, J. S., A. Collins, et al. (1989). "Situated cognition and the culture of learning." Educational researcher 18(1): 32-42.

${ }^{6}$ Colby, A. Ehrlich, T., Baumont, E., \& Stephen, J. (2003) Educating Citizens: Preparing America's Undergraduates for Lives of Moral and Civic Responsibilities, San Francisco, CA: Jossey-Bass.

${ }^{7}$ Zlotkowski, E. (1999) Pedagogy and Engagement, in Bringle, R., Games, R, Molley, E., (Eds) College and Universities as Citizens (pp.96-120), Boston: Allyn \& Bacon.

${ }^{8}$ Erickson, J., \& Anderson, editors (1997) Learning with the Community, Concepts and Models for Service-Learning in Teacher Education, Washington, D.C. American Association for Higher Education.

9 Jacoby, B. (1996) Service-learning in today's higher education. In B. Jocoby and Associates. (Eds.) Service-Learning in Higher Education: Concepts and Practices. San Francisco: John Wiley \& Sons/ Jossey Bass. 
${ }^{10}$ Marullo, S. (1997). "The Service_Learning Movement in Higher Education: An American Response to Troubled Times.” Sociological Imagination 33: 117-137.

${ }^{11}$ Bringle, R., Hatcher, J \& Games. (1997) Engaging and Supporting Faculty in ServiceLearning: The Journal of Public Service and Outreach 2 (1), 43-51.

${ }^{12}$ Stanton, T., Giles, D. Jr., and Cruz, N. (1999) Service-Learning: A Movement's Pioneers Reflect on its Origins, Practice and Future. San Francisco, CA: Jossey-Bass.

${ }^{13}$ Howard, J. (Ed.). (2001). Service-learning course design workbook. Ann Arbor, MI: Mighigan Journal of Community Service-learning OCSL Press.

${ }^{14}$ Tsang, E., (2002) Using Assessment to Develop Service-Learning Reflection Course Materials, Frontiers in Education 32 Annual Vol. 2.

${ }^{15}$ Slivovsky, Lynne A., et al. "An analysis of the reflection component in the epics model of service learning." Proceedings of the American Society for Engineering Education Annual Conference and Exposition, Salt Lake, UT. 2004.

${ }^{16}$ Lathem, Sandra A., Maureen D. Neumann, and Nancy Hayden. "The socially responsible engineer: Assessing student attitudes of roles and responsibilities." Journal of Engineering Education 100.3 (2011): 444-474.

${ }^{17}$ Colledge, T. (Ed.) ( 2012) Convergence: Philosophies and Pedagogies for Developing the Next Generation of Humanitarian Engineers and Social Entrepreneurs. International Journal for Service-Learning in Engineering.

${ }^{18}$ Johnson, D., Johnson, R., \& Smith, K. (1991) Cooperative Learning. HSHE-ERIC Higher Education Reports, Washington, D.C. The George Washington University, School of Education Human Development.

${ }^{19}$ Twombly, S. B.,(1995) Students Perspectives on General Education in a Research University: An Exploratory Study in Conrad, C. F. \& Haworth, J. G. (Ed) Revisioning Curriculum in Higher Education, Needham Heights, MA. Simon \& Schuster Custom Publishing.

${ }^{20}$ Barr, R. B., \& Tagg, J. A New Paradigm for Undergraduate Education in November/December 1995, Change Magazine.

${ }^{21}$ Freire, P. (1970). Pedagogy of the Oppressed. New York: Seabury Press. 
International Journal for Service Learning in Engineering Vol. 9, No. 2, pp. 29-46, Fall 2014

ISSN 1555-9033

${ }^{22}$ Pascarella, E. \& Tarenzini, P. (1991) How College Affects Students: Findings and Insight from Twenty Years of Research. San Francisco, CA: Jossey-Bass Publishers.

${ }^{23}$ Eyler, J., \& Giles, D. (1999) Where is the Learning in Service-Learning? San Francisco: Jossey-Bass.

${ }^{24}$ Dewey, J. (1938). Experience and Education. New York: Collier Books, Macmillan.

${ }^{25}$ Schon, D. A. (1987). Educating the reflective practitioner: Toward a new design for teaching and learning in the professions. San Francisco: Jossey-Bass Publishers.

${ }^{26}$ Astin, A. W., Vogelgesang, L. J. Ikeda, E. K., \& Yee, J. A. (2000) How Service-Learning Affects Students. Los Angeles: University of California, Los Angeles, Higher Education Research Institution.

${ }^{27}$ Morton, Keith, and Marie Troppe. "From the margin to the mainstream: Campus Compact's project on Integrating Service with Academic Study." Journal of Business Ethics 15.1 (1996): 21-32.

28 Stanton, T., Giles, D. Jr., and Cruz, N. (1999) Service-Learning: A Movement's Pioneers Reflect on its Origins, Practice and Future. San Francisco, CA: Jossey-Bass.

${ }^{29}$ Hatcher, J. \& Bringle, R (1999). Rlections: Bridging the gap between service and learning, National Society for Experiential Education, 24 (3), 12-16. Originally appeared in College Teaching, 1997, 45 (4), 153-158.

${ }^{30}$ Eyler, J., \& Giles, D. (1999) Where is the Learning in Service-Learning? San Francisco: Jossey-Bass.

${ }^{31}$ Springer, N., C. and McKight Casey, K., (2010). "From "Preflection" to Reflection: Building Quality Practices in Academic Service-Learning." in Fitzgerald, H. E., Burack, C., and Seifer, S. D edited Handbook of Engaged Scholarship: Contemporary Landscapes, Future Directions, Volumr 2 Community-Campus Partnerships, Michigan State University Press, East Lansing, Michigan.

${ }^{32}$ Tsang, E., (2002) Using Assessment to Develop Service-Learning Reflection Course Materials, Frontiers in Education 32 Annual Vol. 2.

${ }^{33}$ Battistoni, R.M., (2002) Civic Engagement Across the Curriculum, A resource book for service-learning faculty in all disciplines, Campus Compact. 
International Journal for Service Learning in Engineering Vol. 9, No. 2, pp. 29-46, Fall 2014

ISSN 1555-9033

${ }^{34}$ Newell, F. H. (1922). "Ethics of the engineering profession." The Annals of the American Academy of Political and Social Science: 76-85.

${ }^{35}$ Lang, J. D., Cruse, S., McVey, F. D., \& McMasters, J. (1999). Industry expectations of new engineers: A survey to assist curriculum designers. Journal of Engineering Education, 88(1), 4351.

${ }^{36}$ Eyler, J., Root, S., \& Giles, D. (1998) "Service-Learning and the Development of Expert Citizens.” In Bringle, R., \& Duffey, D. (eds). Monograph on Service-Learning and Psychology. American Association for Higher Education. Washington. D.C.

${ }^{37}$ Eyler, J., Root, S., \& Giles, D. (1998) "Service-Learning and the Development of Expert Citizens." In Bringle, R., \& Duffey, D. (eds). Monograph on Service-Learning and Psychology. American Association for Higher Education. Washington. D.C.

${ }^{38}$ Valle, A., Cabanach, ., Rodriguez, S., et al. (2011) A Motivational Perspective on the SelfRegulated Learning in Higher Education, Journal of Education Research Vol5, Number 3/4, Nova Science Publishers, Inc.

${ }^{39}$ Valle, A., Cabanach, ., Rodriguez, S., et al. (2011) A Motivational Perspective on the SelfRegulated Learning in Higher Education, Journal of Education Research Vol5, Number 3-4, Nova Science Publishers, Inc.

${ }^{40}$ Stake, R. E. (2005) Qualitative Case Studies. In N.K. Denzin \& Y.S. Lincoln (Eds.) The Sage Handbook of Qualitative Research (3rd.) Thousand Oaks, CA: Sage Publications.

${ }^{41}$ Merriam, S. B. (1998). Qualitative research and case study applications in education. San Francisco, CA: Jossey-Bass Publishers.

${ }^{42}$ Glesne, C. (1999). Becoming qualitative researchers: An introduction (2nd ed.). New York: Addison Wesley Longman.

${ }^{43}$ Cresswell, J. W. (2003). Research design: Qualitative, quantitative, and mixed methods approaches. Thousand Oaks, Ca: Sage Publications.

${ }^{44}$ ABET (2010) Criteria for Accrediting Engineering Programs, Effective for Evaluations During the 2011-2012 Accreditation Cycle, 26 pp., ABET Engineering Accreditation Commission. www.abet.org. 
${ }^{45}$ Gelmon, S., Holland, B., Driscoll, A., Spring, A., \& Kerrigan, S. (2001) Assessing ServiceLearning and Civic Engagement: Principles and Techniques, Campus Compact, pp 19-27. Brown University, Providence, RI.

${ }^{46}$ Valle, A., Cabanach, ., Rodriguez, S., et al. (2011) A Motivational Perspective on the SelfRegulated Learning in Higher Education, Journal of Education Research 5 (3-4), Nova Science Publishers, Inc.

${ }^{47}$ Hatcher, J. \& Bringle, R (1999). Rlections: Bridging the gap between service and learning, National Society for Experiential Education, 24 (3), 12-16. Originally appeared in College Teaching, 1997, 45 (4), 153-158. 